\title{
Multidrug-Resistant Tuberculosis in Prison Inmates, Azerbaijan
}

\author{
Gaby E . Pfyffer,* Anni Strässle,* Tamara van G orkum,† Françoise Portaels,‡ \\ Leen Rigouts,‡ Christine Mathieu,§ F uad Mirzoyev,§ Hamidou Traore,‡ and \\ J an D.A. van E mbdent \\ *University of Zurich, Zurich, Switzerland; †National Institute of Public Health and \\ Environmental Protection, Research Laboratory for Infectious Diseases, Bilthoven, \\ the Netherlands; ¥Institute of Tropical Medicine, Antwerp, Belgium; and §I nternational \\ Committee of the Red Cross, Geneva, Switzerland
}

\begin{abstract}
In a tuberculosis (TB) program in the Central Penitentiary Hospital of Azerbaijan, we analyzed 65 isolates of Mycobacterium tuberculosis by IS6110based restriction fragment-length polymorphism (RFLP) and spoligotyping. From 11 clusters associated with 33 patients, 31 isolates had an IS6110based banding pattern characteristic of the Beijing genotype of $M$. tuberculosis. In addition, $15 \mathrm{M}$. tuberculosis isolates with similar RFLP patterns constituted a single group by spoligotyping, matching the Beijing genotype. Multidrug resistance, always involving isoniazid and rifampin, was seen in $34(52.3 \%)$ of 65 isolates, with 28 belonging to the Beijing genotype.
\end{abstract}

Tuberculosis (TB) is an important health problem in prison settings (1), where factors such as poor general health of inmates, overcrowding, increased risk factors, delayed case finding, and incomplete or inadequate therapeutic intervention contribute to rapid spread (2) and high prevalence (e.g., 500 cases per 100,000 inmates in New York City jails [3] and 2,283 per 100,000 inmates in the General Penitentiary Hospital in Madrid, Spain [4]). In prisons of the former Soviet Union, TB incidence is even higher (e.g., in Siberia [5] or Russia as a whole [6,7]). TB incidence is also associated with length of incarceration (3). Transmission patterns are generally difficult to establish (8), and the rate of unrecognized transmission may be quite high (9). Above all, strains isolated in these settings are often multidrug resistant (MDR) $(10,11)$.

According to the International Committee of the Red Cross (ICRC), the total number of inmates in the Azerbaijan prison system is approximately 25,000 . With 4,667 TB cases per 100,000, the incidence in Azeri prisons is nearly 50 times higher than the country average, and the mortality rate may reach $24 \%$ (6). In J une 1995, the ICRC implemented a TB control program in the Central Penitentiary Hospital in Baku, Azerbaijan, which was the only treatment center for Azeri prisoners with TB. The program was based on directly observed therapy, short course (DOTS), as recommended by the World Health Organization (WHO [12]) and the International Union Against Tuberculosis and Lung Disease (IUATLD [13]). After treatment failures were observed despite completion of strictly supervised therapy, susceptibility testing of inmates' M. tuberculosis isolates demonstrated a high rate of multidrug resistance (11).

Address for correspondence: Gaby E. Pfyffer, Swiss National Center for Mycobacteria, Department of Medical Microbiology, University of Zurich, Gloriastrasse 30, 8028 Zurich, Switzerland; fax: 411-6344918; e-mail: pfyffer@immv.unizh.ch
Several outbreaks of MDR-TB have been reported worldwide from hospitals (affecting patients and health-care workers [14]), the community (15), and prisons (4). In these outbreaks, MDR-TB has predominantly affected immunocompromised patients, and disease was often caused by certain strains of M. tuberculosis, in particular the W strain (16-18). This strain and its many variants (e.g., subtypes $W_{1}$ [17] and U [19]), form a family lineage that shares a common genotype with the Beijing clone (20). At the molecular level, they exhibit a closely related, unique multiband IS6110based restriction fragment-length polymorphism (RFLP) pattern and contain 9 of 43 polymorphic spacer sequences in the chromosomal DR locus by spoligotyping (21).

We report the genotypic characterization and spread of predominantly MDR M. tuberculosis strains in a prison in Azerbaijan. Along with IS6110-based RFLP, spoligotyping, and drug-susceptibility profiles, we have determined the type of mutation in the rpoB gene responsible for resistance to rifampin (RMP).

\section{Methods}

\section{Patients}

At the beginning of the ICRC program, 65 male patients 19 to 55 years of age were included in the study. All were from Azerbaijan, and their terms of imprisonment ranged from 6 months to 20 years. Once diagnosed as having smearpositive pulmonary TB, they were transferred to the Central Penitentiary Hospital in Baku, the referral hospital for the Azerbaijan prison system. No clinical histories were available for the time before the ICRC intervention. Personal characteristics have largely been provided by the prisoners themsel ves (Table). Patients were classified at admission on the basis of their self-recorded anti-TB drug intake as nonresponders (patients who were treated with single or multiple drugs for $>1$ month and continued to be smear-positive 


\section{Research}

Table. Characteristics of the cohort of prison inmates with tuberculosis, Azerbaijan

\begin{tabular}{|c|c|c|c|c|c|}
\hline Strain no. & $\begin{array}{l}\text { Age of patient } \\
\text { (years) }\end{array}$ & $\begin{array}{l}\text { Body mass } \\
\text { index }\end{array}$ & Patient group ${ }^{a}$ & Onset of symptoms & $\begin{array}{l}\text { Previous treatment (before enrollment in } \\
\text { ICRC program) })^{\mathrm{b}}\end{array}$ \\
\hline 7887 & 40 & -- & A & J an 1995 & $H, R, E, S$ \\
\hline 7909 & 40 & 16.1 & A & J un 1995 & $\begin{array}{l}\text { S (4 mo. in 1995) } \\
\text { S (1 mo. in 1996) }\end{array}$ \\
\hline 7920 & 22 & 16.3 & A & Mar 1995 & $H(?), R(?), S$ \\
\hline 7101 & 20 & -- & B & J an 1996 & $\mathrm{~S}$ \\
\hline 5691 & 26 & -- & A & Feb 1995 & $\mathrm{~S}$ \\
\hline 7915 & 21 & 16.2 & B & Mar 1996 & None \\
\hline 7922 & 33 & 16.1 & A & Spring 1996 & $H, R, E, S$ \\
\hline 7908 & 32 & 16.1 & B & Mar 1996 & $R, E, S$ \\
\hline 7930 & 21 & 16 & B & Aug 1996 & $R, E, S$ \\
\hline 7935 & 23 & 17.3 & B & Mar 1996 & $\mathrm{R}$ \\
\hline 7925 & 22 & 19.3 & A & Feb 1996 & $\begin{array}{c}\mathrm{S} \text { (monotherapy initially); R,E,S } \\
\text { ( } 2 \text { to } 3 \text { mo.) }\end{array}$ \\
\hline 7931 & 21 & 16 & B & J ul 1996 & $\mathrm{R}, \mathrm{S}$ \\
\hline 7914 & 34 & 15.7 & A & Nov 1995 & $\mathrm{R}, \mathrm{E}, \mathrm{S}$ (not completed) \\
\hline 5713 & 25 & 15.6 & B & Dec 1995 & $H, R, E, S$ \\
\hline 7910 & 32 & 17.5 & A & Feb 1996 & S,E (not completed) \\
\hline 7900 & $?$ & 20.2 & A & J ul 1995 & $\begin{array}{l}H, R, S(\text { in 1995) } \\
\quad S(\text { in 1996) }\end{array}$ \\
\hline 5697 & 19 & 17.4 & B & Mar 1996 & none \\
\hline 5692 & 22 & -- & A & Feb 1995 & $H, R, E, S$ \\
\hline 7916 & 32 & 18.2 & A & 1994 & $\begin{array}{c}\mathrm{H}, \mathrm{R}, \mathrm{E}, \mathrm{S}, \mathrm{K} \text { (several } \leq 3-\text { mo.intervals of } \\
\text { treatment) }\end{array}$ \\
\hline 7932 & 22 & 18.1 & C & Nov 1993 & $\begin{array}{l}\mathrm{H}, \mathrm{R}, \mathrm{E}, \mathrm{S}, \mathrm{K} \text { (several intervals of } \\
\text { treatment: } 1 \text { mo., } 4 \text { mo., } 12 \text { mo.) }\end{array}$ \\
\hline 5700 & 34 & 18 & B & Feb 1996 & none \\
\hline 5702 & 26 & 18.1 & A & Sep 1995 & $\mathrm{~S}$ \\
\hline 5706 & 23 & -- & B & Feb 1996 & $\mathrm{~S}$ \\
\hline 5716 & 24 & 19 & B & Feb 1996 & $\mathrm{R}, \mathrm{S}$ \\
\hline 7888 & 30 & -- & A & Oct 1994 & $H, R, E, K(<2$ mo. in 1994) H,R (in 1995) \\
\hline 5693 & 26 & 17.2 & B & J an 1996 & $\mathrm{~S}$ \\
\hline 5722 & 26 & 17.1 & B & Dec 1995 & $H, R, E, S, K$ \\
\hline 7895 & 19 & 18.5 & B & J un 1996 & $H, R, S$ \\
\hline 5724 & 37 & 17.3 & B & Dec 1995 & $H, R, E, S$ \\
\hline 7886 & $46^{c}$ & -- & A & Mar 1995 & $\mathrm{R}, \mathrm{E}, \mathrm{S}$ (not completed) \\
\hline 7917 & 55 & -- & C & 1987 & $\mathrm{R}, \mathrm{E}, \mathrm{S}$ (11 mo.) \\
\hline
\end{tabular}




\section{Research}

Table. (continued) Characteristics of the cohort of prison inmates with tuberculosis, Azerbaijan

\begin{tabular}{|c|c|c|c|c|c|}
\hline Strain no. & $\begin{array}{l}\text { Age of patient } \\
\text { (years) }\end{array}$ & $\begin{array}{l}\text { Body mass } \\
\text { index }\end{array}$ & Patient group ${ }^{a}$ & Onset of symptoms & $\begin{array}{l}\text { Previous treatment (before enrollment in } \\
\text { ICRC program) }\end{array}$ \\
\hline 7933 & 25 & 18.2 & $A$ & Aug 1996 & $R, E, S$ \\
\hline 5718 & 20 & 17.6 & B & Oct 1995 & $\mathrm{H}, \mathrm{K}$ \\
\hline 7889 & $?$ & -- & $A$ & $?$ & $?$ \\
\hline 7921 & 22 & 19.4 & B & J ul 1996 & $\mathrm{~S}$ \\
\hline 7926 & 20 & $--^{c}$ & B & Aug 1996 & none \\
\hline 7927 & 32 & 18.4 & $A$ & Mar 1996 & H,E S (not completed) \\
\hline 7904 & 21 & 16.8 & B & May 1996 & $\mathrm{H}, \mathrm{S}$ \\
\hline 7929 & 47 & 26.3 & $A$ & May 1996 & $\mathrm{R}, \mathrm{E}, \mathrm{S}$ (not completed) \\
\hline 7894 & 28 & 17.3 & B & Apr 1996 & None \\
\hline 7902 & 25 & 19.2 & $A$ & 1995 & $\mathrm{H}, \mathrm{S}(6 \mathrm{mo}.) \mathrm{R}, \mathrm{E},(7 \mathrm{~d})$ \\
\hline 5686 & 29 & -- & A & May 1995 & $\mathrm{H}, \mathrm{R}, \mathrm{E}, \mathrm{S}$ (not completed) \\
\hline 5694 & 29 & 17.3 & $A$ & J an 1995 & H,S (1 mo. in 1995) E,S (1 mo. in 1996) \\
\hline 5726 & 44 & 16.9 & A & $?$ & $\begin{array}{c}H, R, E, S(3 \text { to } 4 \text { mo. in 1991) } H, R, E, S \text { (in } \\
\text { 1995) }\end{array}$ \\
\hline 7911 & 34 & 17.9 & B & Mar 1995 & $R, E, S, K$ \\
\hline 5688 & 37 & -- & A & Sep 1994 & $R, E, S$ \\
\hline 5687 & 41 & 20.3 & B & Feb 1996 & $E, S$ \\
\hline 5729 & 40 & 16.3 & $\mathrm{C}$ & 1994 & $\mathrm{R}, \mathrm{S}$ (3 mo. in 1994) S (in 1996) \\
\hline 7890 & 19 & -- & A & 1994 & $H, E, S(3$ mo. in 1994) R,E,S (in 1996) \\
\hline
\end{tabular}

[group A; $\mathrm{n}=30$ ]), new cases (smear-positive patients who had never been treated or were treated for $<1$ month [group $\mathrm{B} ; \mathrm{n}=31]$ ), and relapsed cases (patients who had active TB and were treated and considered clinically cured but became smear-positive again [group $C ; n=4]$ ).

\section{Microbiologic Diagnosis and Drug Susceptibility Testing}

Sputum specimens were analyzed for the presence of acid-fast bacilli (Ziehl-Neelsen staining) by the local microbiology laboratory, which was supervised by the ICRC. Processing of specimens, culture, and identification of $M$. tuberculosis were done in Zurich or Antwerp according to standard procedures (22). Susceptibility testing of M. tuberculosis to primary drugs (isoniazid, RMP, ethambutol, and pyrazinamide) plus streptomycin was performed in liquid medium by the radiometric BACTEC 460 TB system (Becton Dickinson, Sparks, MD) (23) and confirmed by the agar proportion method (22).

\section{Molecular Characteristics of RMP Resistance}

All M. tuberculosis isolates were analyzed by the I N NOLiPA-Rif TB Assay (I nnogenetics, Ghent, Belgium) (24). This reverse hybridization-based line probe assay carries one oligonucleotide probe for the detection of M. tuberculosis com- plex strains and nine probes to detect nucleotide changes in the relevant part of the rpoB gene.

\section{Molecular Epidemiology}

Pvull-digested DNA of M. tuberculosis was probed with the insertion element IS6110 according to the standardized protocol of van Embden et al. (25), with some modifications (26). "Cluster strains" had 100\% identical RFLP patterns.

\section{Cluster Analysis}

I S6110-based RFLP patterns were analyzed by GelCompar software (Windows 95, version 4.0; Applied Math, Kortrijk, Belgium) with an HP Scanj et 4c (Hewlett Packard, Greeley, CO; scanned at $190 \mathrm{dpi}$ ). The mobility of the IS6110 fragments was compared with the molecular weight marker lambda-DNA EcoRI/HindlII (Roche Diagnostics, Rotkreuz, Switzerland), which was used as external size marker. In addition, the accuracy of the procedure was tested by comparing the IS6110 banding pattern of $\mathrm{M}$. tuberculosis isolate Mt14323, which was present on each autoradiograph. Patterns were compared by the UPGMA clustering method with the Dice coefficient (1.2\%). Spoligotype patterns (27) generated from all 65 isolates were compared visually. 


\section{Research}

\section{Results}

Except for two patients in whom the first symptoms of TB had appeared 9 and 20 years previously, the patients had recent onset of TB disease (Table). M ost prisoners were substantially undernourished (as indicated by low body mass indices) and in poor clinical condition, many with unilateral or bilateral pulmonary infiltrates and cavities. Most of the nonresponding patients (group A) had been treated inade quately before the ICRC intervention (Table).

Based on morphologic and biochemical characteristics, all 65 isolates were identified as classical M. tuberculosis. Hybridization of Pvull-digested chromosomal DNA with the 245-bp fragment of IS6110 resulted in variable patterns, although to a limited degree (Figure 1). Within a cluster (each cluster comprising a minimum of 2 and a maximum of 10 patients), isolates had identical IS 6110 patterns. Overall,

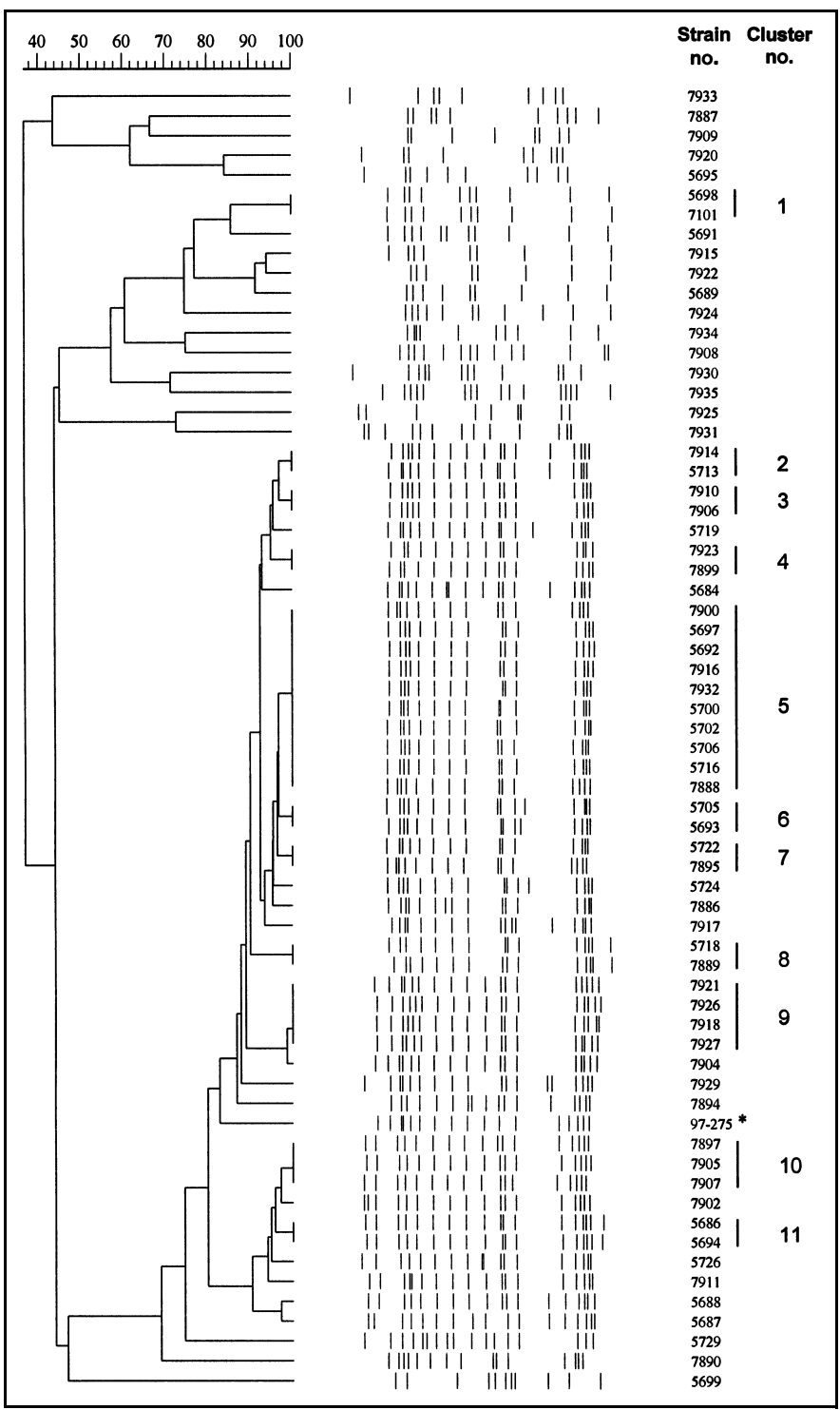

Figure 1. Computer-generated lane maps of genomic fingerprints of Mycobacterium tuberculosis strains isolated from the patient cohort $(n=65)$. P vul I-digested chromosomal DNA was probed with IS6110. Clusters 1 to 11 are indicated by vertical lines at the right margin. Asterisk indicates strain 97-275 (Beijing clone, obtained from $\mathrm{K}$. Kremer, RIVM/NL) for comparison. Strains 7914 through 5687 show the Beijing genotype restriction fragment-length polymorphism pattern. The molecular weight marker and internal reference strain of M. tuberculosis (Mt 14323) are not shown. we found 11 clusters containing a total of 33 isolates. Apart from cluster 1 , which consisted of 2 isolates with 10 IS6110 copies, the isolates bel onging to clusters 2 to 11 were characterized by 15 to 18 IS6110 fragments and similar banding patterns (similarities of $>90 \%$ for clusters 2 to 9 and $>80 \%$ for clusters 10 and 11 with the former group). In addition to the 31 isolates of clusters 2 to 11,15 other isolates of $\mathrm{M}$. tuberculosis displayed similar IS6110 patterns, differing in the presence or absence of one or two bands or in the IS6110 fragment length (Figure 1 ). These 15 isolates were highly related $(268 \%)$ to those of clusters 2 to 11 . DNA fingerprints of the 31 isolates in clusters 2 to 11 and the 15 closely associated isolates strongly resembled the Beijing genotype of $M$. tuberculosis (Figure 1, asterisk).

Spoligotyping grouped those 46 isolates into one genotype with identical spoligotypes that lacked all but 9 of the 43 DR spacers and thus resembled the Beijing family of $M$. tuberculosis. The remaining 19 isolates of the patient cohort resulted in different, mostly individual spoligotypes (Figure 2). While cluster 1 was confirmed by spoligotyping, other isolates, mostly with a high degree of similarity in their RFLP patterns, were also grouped together (isolates 7887/5695/ 7920; isolates 5691/5689; isolates 7922/7915; and isolates 7908/7935; Figure 2).

Regardless of Beijing or other types, the susceptibility patterns differed, ranging from fully susceptible to resistant to one or more drug(s). Overall, $52.3 \%$ of the strains isolated from the cohort (Figure 2) and $60.9 \%$ (28/46 isolates) in the group of Beijing type strains were MDR. While none of the RMP-susceptible strains carried a mutation in the relevant part of the rpoB gene, all strains resistant to RMP (by growth-based susceptibility testing) were correctly identified by the INNO-LiPA-Rif assay. F or 22 of them, the type mutation was detected: D516V (R2; $n=1), H 526 Y(R 4 a ; n=2)$, H526D (R4b; $n=1)$, and S531L (R5; $n=18)$. S531L was predominant in the Beijing family (17/28 RMPR isolates = $60.7 \%$; Figure 2. MDR strains of $M$. tuberculosis were found in 19 of 30 patients in group A, 14 of 31 patients in group B, and 1 of 4 patients in group $C$. Full drug susceptibility was also seen in all groups of patients ( 3 of 30 in group A, 7 of 31 in group $B$, and 1 of 4 in group $C$ ).

\section{Conclusion}

Analyzing the TB patients in the Central Penitentiary Hospital in Baku was complicated by constraints and biases inherent in the prison environment. Clinical information on the prisoners was limited and mainly based on self-reported data. Conclusions based on analysis of 65 of the approximately 300 TB patients in that hospital are largely fragmentary and may not be truly representative. However, enrolling more patients into our pilot study was not considered, mainly because of frequent transfer of prisoners and high mortality rates. When the DOTS program was implemented by the ICRC, many of the TB patients were either untreated or had received inadequate drug regimens for years.

Although we analyzed a limited number of patients, our study demonstrates that most strains $(70.8 \%)$ belonged to the Beijing family of $M$. tuberculosis and that multidrug resistance was a serious problem (52.3\%) in this setting. The Beijing genotype, characterized by 15 to 18 IS6110 copies and a specific spoligotype pattern, was identified in 10 of the 11 clusters ( 2 to 11 ) and included isolates of 31 patients, plus 


\section{Research}

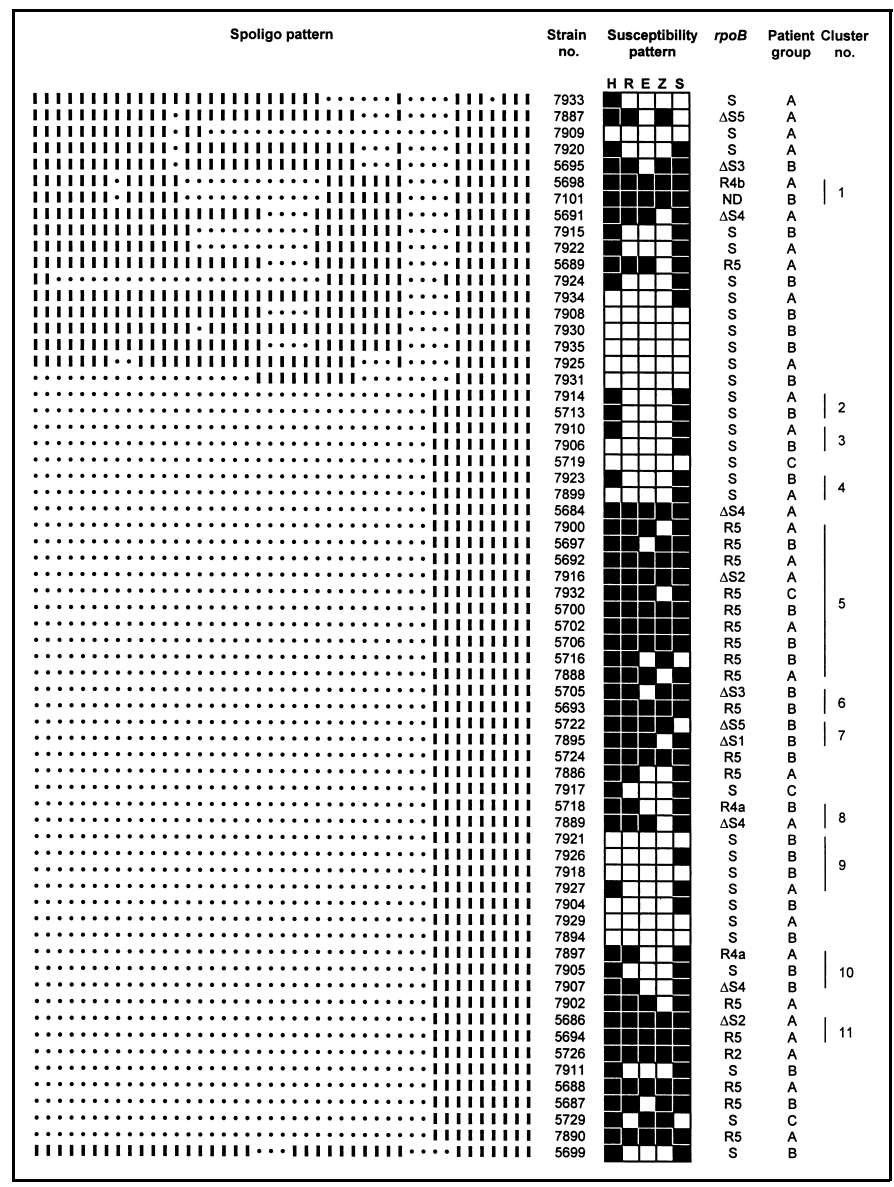

Figure 2. Spoligotypes of the 65 strains of M. tuberculosis analyzed, drug susceptibility patterns, and type of mutation on the rpoB gene conferring rifampin resistance ( $r p o B)$. $H$ =isoniazid; $\mathrm{R}=$ rifampin; $\mathrm{E}$ $=$ ethambutol; $Z$ = pyrazinamide; $S=$ streptomycin. Black fields indicate resistance; blank ones susceptibility. $S=$ wild type $\left(R M P^{S}\right)$ mutations (RMPR): $\Delta \mathrm{S} 1 ; \mathrm{DS} 2 ; \Delta \mathrm{S} 3 ; \Delta \mathrm{S} 4 ; \Delta \mathrm{S} 5 ; \mathrm{R} 2 ; \mathrm{R} 4 \mathrm{a} ; \mathrm{R} 4 \mathrm{~b} ; \mathrm{R} 5 ; \mathrm{ND}$ $=$ not done. Group $A=$ nonresponders; Group B = new cases; and Group C $=$ relapsed cases.

isolates from an additional 15 patients that had a high similarity with the cluster strains on IS6110-based DNA fingerprinting. Sharing most of the IS6110-containing restriction fragments and the polymorphism associated with other repetitive DNA elements (28), the Beijing done of $M$. tuberculosis has been isolated predominantly from patients in the People's Republic of China and neighboring Asian countries such as Mongolia, Korea, and Thailand (20). The emergence of the Beijing clone is now also well documented in Vietnam: Anh et al. have shown that 304 (54\%) of 563 isolates studied were of that genotype and associated with younger patients and, hence, with active transmission (29).

In the three patient groups, only 11 isolates of $M$. tuberculosis were fully drug susceptible (2 patients in group $A ; 7$ patients in $B$; and 1 patient in $C$ ). Dual resistance to isoniazid and streptomycin was seen in 10 cases (4 in A and 6 in B). Multidrug resistance was particularly associated with the Beijing genotype $(28 / 46=61 \%$ versus $6 / 19=31 \%$ with the non-Beijing type) and, as expected, most frequent in patients of group A (19 in A, 14 in B, and 1 in C). For strains of the Beijing group whose mutation types could be determined, substitution at ser ${ }^{531}$ (mutation type R5) predominated. Published reports indicate that this mutation is the most common point mutation conferring RMP resistance
$(30,31)$. Recently, Naroditskaya et al. (unpub. data) studied 40 MDR-TB isolates from inmates of a prison in Tomsk (Russia) and reported that as many as $77.5 \%$ of the isolates had a substitution of $\mathrm{ser}^{531} \geq \mathrm{leu}$. Of these isolates, $15 \mathrm{had}$ an RFLP pattern (W148) specific for the so-called W-strain family, which is highly drug-resistant and belongs to the phylogenetic lineage of the Beijing family. W and W-like strains have been associated with large MDR-TB outbreaks in the United States $(16,17)$ and elsewhere (e.g., South Africa [19]). With high disease and mortality rates, MDR outbreaks caused by the $\mathrm{W}$ strain family and its variants have mainly affected HIV-infected persons $(17,18)$ but affect HIV-negative persons as well $(19,32)$. The HIV status of our cohort remained unknown, since the prisoners had not been tested. We assume that HIV infection has had little influence, since its incidence in the general Azeri population is low (33).

The difficulty in establishing transmission links among prisoners is well known. Although ample clinical information about their patients was available, J ones et al. (8) were unable to identify specific person-to-person lines of transmission among most inmates in a North American jail. Having been unable to establish accurate links among inmates or to define index patient(s) in the Baku Penitentiary Hospital, we can only hypothesize possible modes of transmission; for example, some patients may have contracted TB in the community long before they were imprisoned. Political constraints prevented us from studying TB strains in the Azeri population, which would have allowed us to analyze the molecular genetic composition of the strains circulating in the community, as well as to estimate the prevalence of the Beijing genotype strains. Acquisition of TB disease within the prison walls is, however, morelikely. I dentical RFLP patterns and spoligotypes, as well as identical susceptibility patterns, including the same point mutation in the rpoB gene (e.g., isolates 5692, 5700, 5702, 5706, 7932, and 7888 of cluster 5) suggest recent person-to-person transmission of TB. Nevertheless, we could not establish that the isolates of the large cluster carrying an S531L mutation are all derived from the same index strain. Since this mutation is by far the most frequent one, it could also have arisen independently in some of these strains.

Recent transmission within the prison is questionable for those cluster strains that are identical by RFLP, spoligotype and susceptibility profiles but have distinct mutations in the rpoB gene (e.g., isolate 7916 [cluster 5: $\Delta$ S2] versus all other isolates of this cluster [R5]; isolates 7897 and 7907 [cluster 10: R4a and $\Delta$ S4]; isolates 5686 and 5694 [cluster 11: $\Delta \mathrm{S} 2$ and R5]). Thus, in all these cases TB is most likely not the result of recent transmission from a single source, which would require an RMP-susceptible progenitor strain. The fact that different susceptibility patterns were detected among the Beijing strains may indicate that transmission in the prison primarily involved RMP-susceptible strains, with resistance to RMP (and other drugs) evolving gradually in individual patients.

From this study, several conclusions can be drawn: MDR-TB is a substantial problem in Azeri prisons; the Beijing clone of $M$. tuberculosis was found in all three patient groups (nonresponders, new cases, and relapsed cases) and had a high rate of multidrug resistance; modes of transmission remain unclear, i.e., TB may have been acquired in different ways (outside or inside the prison); and MDR-TB in 


\section{Research}

this cohort may result from recent transmission in the prison, but may also have evolved as a result of longstanding, inadequate treatment regimens.

Unless WHO/UATLD-recommended treatment schemes are followed, the problem of TB, in particular of MDR-TB, may become more widespread (8). In response, both $\mathrm{WHO}$ and ICRC have developed guidelines for managing TB in prisons (2). Special emphasis has to be put on settings where TB strains have a high degree of resistance, since regimens with first-line antibiotics may not be sufficient, as demonstrated by Coninx et al. (34). To achieve TB control in prisons, multiple goals need to be attained: efficient diagnosis to permit early case finding, prompt initiation of standardized treatment, monitoring of patient response to treatment, and provisions for ample supply of anti-TB drugs that meet quality standards.

\section{Acknowledgments}

We thank E. Aresheva in Baku and R. Wirth in Zurich for excellent technical assistance, and R. de Haller in Geneva and A. von Graevenitz in Zurich for valuable discussions and suggestions.

This project received financial support from the Belport Foundation (Zurich).

Dr. Pfyffer is professor of medical microbiology, Department of Medical Microbiology, and head of the Swiss National Center for Mycobacteria, both at the University of Zurich. Her research interests include the chemical and molecular taxonomy of mycobacteria, DNA fingerprinting and other typing methods, and new techniques for drug susceptibility testing and growth and detection of mycobacteria.

\section{References}

1. Drobniewski F. Tuberculosis in prisons-the forgotten plague. Lancet 1995;346:948-9.

2. Maher D, Grzemska M, Coninx R, Reyes H. Guidelines for the control of tuberculosis in prisons. World Health Organization and International Committee of the Red Cross. Geneva: WHO and ICRC (WHO/TB/98.250); 1998.

3. Bellin EY, Fletcher DD, Safyer SM. Association of tuberculosis infection with increased time in or admission to the New York City J ail System. J AM A 1993;269:2228-31.

4. Chaves F, Dronda F, Cave MD, Alonso-Sanz M, Gonzal ez-L opez A, Eisenach KD, et al. A longitudinal study of transmission of tuberculosis in a large prison population. Am J Respir Crit Care Med 1997:155:719-25.

5. Drobniewski F, Tayler E, I gnatenko N, Paul J, Connolly M, Nye $P$, et al. Tuberculosis in Siberia-an epidemiological and microbiological assessment. Tuberc Lung Dis 1996;77:199-206.

6. Coninx R, Eshaya-Chauvin B, Reyes H. Tuberculosis in prisons. Lancet 1995;346:1238-9.

7. Wares DF, Clowes $\mathrm{Cl}$. Tuberculosis in Russia. Lancet 1997;350:957.

8. J ones TF, Craig AS, Valway SE, Woodley CL, Schaffner W. Transmission of tuberculosis in a jail. Ann Intern Med 1999;131:557-63.

9. Macl ntyre CR, Kendig N, Kummer L, Birago S, Graham NMH, Plant AJ, et al. Unrecognized transmission of tuberculosis in prisons. Eur J Epidemiol 1999;15:705-9.

10. Valway SE, Greifinger RB, Papania M, Kilburn J O, Woodley C, DiFerdinando GT, et al. Multi-drug resistant tuberculosis in the New York State Prison System, 1990-1991. J Infect Dis 1994;170:151-6.

11. Coninx R, Pfyffer GE, Mathieu C, Savina D, Debacker M, $\mathrm{J}$ afarov $\mathrm{F}$, et al. Drug resistant tuberculosis in prisons in Azerbaijan: case study. BMJ 1998;316:1423-5.

12. World Health Organization. WHO report on the tuberculosis epidemic, 1995: Stop TB at the source. Geneva: WHO (WHO/ TB/95.183); 1995
13. International Union Against Tuberculosis and Lung Disease Tuberculosis guide for low income countries. 4th ed. Paris: IUATLD; 1996.

14. Edlin BR, Tokars I I, Grieco MH, Crawford J T, Williams I, Sordillo EM, et al. An outbreak of multidrug-resistant tuberculosis among hospitalized patients with the acquired immunodeficiency syndrome. N Engl J Med 1992;326:1514-21.

15. Pearson ML, J ereb J A, Frieden TR, Crawford J T, Davies BJ Dooley SW, et al. Nosocomial transmission of multidrug-resistant Mycobacterium tuberculosis: a risk to patients and health care workers. Ann Intern Med 1992;117:191-6.

16. Agerton TB, Valway SE, Blinkhorn RJ, Shilkret KL, Reves R, Schluter WW, et al. Spread of strain W, a highly drug-resistant strain of Mycobacterium tuberculosis, across the United States. Clin Infect Dis 1999;29:85-92.

17. Bifani PJ, Mathema B, Liu Z, Moghazeh SL, Shopsin B, Tempalski $B$, et al. Identification of a $W$ variant outbreak of Mycobacterium tuberculosis via population-based molecular epidemiology. J AMA 1999;282:2321-7.

18. Frieden TR, Sherman LF, Maw KL, Fujiwara PI, Crawford J T, Nivin B, et al. A multi-institutional outbreak of highly drugresistant tuberculosis: epidemiology and clinical outcomes. J AMA 1996;276:1229-35.

19. Van Rie A, Warren RM, Beyers N, Gie RP, Classen CN, Richardson $\mathrm{M}$, et al. Transmission of a multidrug-resistant Mycobacte rium tuberculosis strain resembling "strain W" among noninstitutionalized, human immunodeficiency virus-seronegative patients. J Infect Dis 1999;180:1608-15.

20. Van Soolingen D, Qian L, de Haas PEW, Douglas J T, Traore H, Portaels $F$, et al. Predominance of a single genotype of Mycobacterium tuberculosis in countries of East Asia. J Clin Microbiol 1995;33:3234-8.

21. Van Soolingen $D$, Borgdorff $M W$, de Haas PEW, Sebek MM, Veen J, Dessens M, et al. Molecular epidemiology of tuberculosis in The Netherlands: a nationwide study during 1993-1997. J Infect Dis 1999;180:726-36.

22. Kent PT, Kubica G. Public health mycobacteriology: A guide for the level III laboratory. Atlanta, GA: Public Health Service, U.S. Department of Health and Human Services, Centers for Disease Control; 1985

23. Siddiqi SH. BACTEC 460 TB System. Product and procedure manual (MA-0029). Sparks, Md.: Becton Dickinson Diagnostic Instrument Systems; 1995.

24. Rossau R, Traore $H$, de Beenhouwer $H$, Mijs W, J annes G, De Rijk P, et al. Evaluation of the INNO-LiPA Rif. TB assay, a reverse hybridization assay for the simultaneous detection of Mycobacterium tuberculosis complex and its resistance to rifampin. Antimicrob Agents Chemother 1997;41:2093-8.

25. Van Embden J D, Cave MD, Crawford J T, Dale J W, Eisenach KD, Gicquel B, et al. Strain identification of Mycobacterium tubercul osis by DNA fingerprinting: recommendations for standardized methodology. J Clin Microbiol 1993;31:406-9.

26. Strässle A, Putnik J, Weber R, Fehr-Merhof A, Wüst J, Pfyffer $\mathrm{GE}$, et al. Molecular epidemiology of Mycobacterium tuberculosis strains isolated from patients in a human immunodeficiency virus cohort in Switzerland. J Clin Microbiol 1997;35:374-8.

27. Kamerbeek J, Schouls L, Kolk A, van Agterveld M, van Soolingen $D$, Kuijper $S$, et al. Simultaneous detection and strain differentiation of Mycobacterium tuberculosis for diagnosis and epidemiology. J Clin Microbiol 1997;35:907-14

28. Kremer K, van Soolingen D, Frothingham R, Haas WH, Hermans PW, Martin C, et al. Comparison of methods based on different molecular epidemiological markers for typing of Mycobacterium tuberculosis complex strains: interlaboratory study of discriminatory power and reproducibility. J Clin Microbiol 1999;37:2607-18

29. Anh DD, Borgdorff MW, Van LN, Lan NTN, van Gorkum T, Kremer $\mathrm{K}$, et al. Mycobacterium tuberculosis Beijing genotype emerging in Vietnam. Emerg Infect Dis 2000;6:302-5.

30. Kapur V, Li LL, I ordanescu S, Hamrick MR, Wanger A, Kreiswirth BN, et al. Characterization by automated DNA sequencing of mutations in the gene (rpoB) encoding the RNA polymerase $B$ subunit in rifampin-resistant Mycobacterium tuberculosis strains from New York City and Texas. J Clin Microbiol 1994;32:1095-8. 


\section{Research}

31. Matsiota-Bernard P, Vrioni G, Marinis E. Characterization of rpoB mutations in rifampin-resistant clinical Mycobacterium tuberculosis isolates from Greece. J Clin Microbiol 1998;36:203.

32. Codina G, Vidal R, Martin-Casabona N, Miravitlles M, Martin C. Multidrug-resistant tuberculosis caused by ' $W$ ' related strains in three immunocompetent foreign-born patients. Int J Tuberc Lung Dis 1999;3:82-3.
33. European Centre for the Epidemiological Monitoring of AIDS. HIV/AIDS surveillance in Europe. Quarterly report (no. 52). Saint Maurice, France: ECEMAIDS, 1996.

34. Coninx R, Mathieu C, Debacker M, Mirzoev F, Ismael ov A, de Haller R, et al. First-line tuberculosis therapy and drug-resistant Mycobacterium tuberculosis in prisons. Lancet 1999;353:969-73. 